\title{
Comparative Esterase Electrophoretic Polymorphism of Escherichia coli Isolates Obtained from Animal and Human Sources
}

\author{
By Ph. GOUlLET* and B. PICARD \\ Laboratoire de Microbiologie, Faculté de Médecine Xavier-Bichat (Université Paris VII), \\ 16 rue Henri Huchard, 75018 Paris, France
}

(Received 4 October 1985; revised 14 February 1986)

\begin{abstract}
To determine whether enzyme electrophoretic polymorphism in Escherichia coli populations was influenced by environmental background, the mobilities of four electrophoretically variable esterases (A, B, C and I) were examined. The distinction between isolates was established by significant differences in the electrophoretic distribution and the genetic diversity coefficient of individual esterases. Principal components analysis on each population and on all strains revealed three groups of allozymes. The first, characterized by slow electrophoretic mobilities of esterase B, was frequently observed in strains obtained from human extra-intestinal infections and rarely in commensal organisms. The second, characterized by fast mobilities of esterases $A$ and $B$, was frequently found in animal isolates. The third, characterized by prominence of the most common mobilities of esterases $B$ and $A$, was recovered in all populations. These results were confirmed by discriminant analysis. Among the 610 strains investigated, 316 electrophoretic types (distinctive combinations of allozymes of the four varieties of esterases) were distinguished, illustrating high esterase polymorphism.
\end{abstract}

\section{INTRODUCTION}

Escherichia coli is a common member of the intestinal flora of warm-blooded vertebrates. Its widespread distribution in vertebrates may explain its high degree of DNA heterogeneity (Brenner et al., 1969, 1972; Brenner \& Falkow, 1971), and the extent of its enzyme electrophoretic polymorphism (Milkman, 1973; Selander \& Levin, 1980; Ochman et al., 1983; Whittam et al., 1983). For ecological and medical reasons, it is relevant to determine whether enzyme electrophoretic polymorphism may be influenced by the nature of the host and whether it may be used to distinguish pathogenic from commensal strains.

Electrophoretic analyses of natural populations of diploid organisms have shown that esterases, which hydrolyse multiple substrates, are often more variable than enzymes which utilize single substrates (Gillespie \& Langley, 1974). In haploid organisms, esterases show electrophoretic diversity, giving reliable information for both specific and subspecific differentiation of enterobacteria (Goullet, 1981; Goullet \& Picard, 1984b). Among E. coli strains studied by us, four varieties of esterases, designated as A, B, C and I, appeared to be electrophoretically variable (Goullet, 1973, 1980; Goullet \& Picard, 1984a). These enzymes, which hydrolyse $\beta$-naphthyl acetate, were easily differentiated from each other by variation of their hydrolytic activity on $\alpha$-naphthyl acetate and $\alpha$ - and $\beta$-naphthyl butyrates, and in their sensitivity to heat and to di-isopropyl fluorophosphate.

The aim of this work was to evaluate the influence of the environment on esterase polymorphism of $E$. coli by comparing electrophoretic mobilities of esterases A, B, C and I in isolates obtained from three distinct sources: animal and human gastro-intestinal tracts and extra-intestinal infections in humans.

Abbreviations: AIS, animal intestinal strains; $E_{1}$, electrophoretic type; GDC, genetic diversity coefficient; HES, human extra-intestinal infection strains; HIS, human intestinal strains; $M_{F}$, electrophoretic mobility; $W E_{t}$, weighted electrophoretic type. 
Table 1. Source of the bacterial strains

\begin{tabular}{|c|c|c|c|c|}
\hline & Group & $\begin{array}{l}\text { No. of } \\
\text { strains }\end{array}$ & Recovered from: & $\begin{array}{l}\text { Geographical source } \\
\text { (France) }\end{array}$ \\
\hline \multirow[t]{3}{*}{ AIS $^{*}$} & $1 \dagger$ & 102 & $\begin{array}{l}\text { Stools from horse, cow, } \\
\text { calf, pig, goat, sheep, } \\
\text { rabbit, chicken }\end{array}$ & $\begin{array}{l}\text { Acheres La Forêt (Seine et } \\
\text { Marne); Fontainebleau (town) } \\
\text { (Seine et Marne); Braine } \\
\text { (Aisne); Marcy (Loir et Cher); } \\
\text { Mereau (Cher) }\end{array}$ \\
\hline & 2 & 45 & $\begin{array}{l}\text { Stools from cow, sheep, } \\
\text { rabbit, pig, chicken, rat }\end{array}$ & $\begin{array}{l}\text { Experimental farm, Commentry } \\
\text { (Allier) }\end{array}$ \\
\hline & 3 & 64 & $\begin{array}{l}\text { Stools from deer, roebuck, } \\
\text { rabbit, hare, fox }\end{array}$ & $\begin{array}{l}\text { Forest of Fontainebleau } \\
\text { (Seine et Marne) }\end{array}$ \\
\hline \multirow[t]{2}{*}{ HIS* } & $\begin{array}{l}4 \dagger \\
5\end{array}$ & $\begin{array}{l}85 \\
31\end{array}$ & $\begin{array}{l}\text { Stools from healthy man } \\
\text { Stools from healthy man }\end{array}$ & $\begin{array}{l}\text { Paris } \\
\text { Paris }\end{array}$ \\
\hline & 6 & 26 & $\begin{array}{l}\text { Stools from non-infected } \\
\text { patient }\end{array}$ & Beaujon hospital, Clichy \\
\hline \multirow[t]{4}{*}{ HES* } & $7 \dagger$ & 66 & Extra-intestinal infections & Durance hospital, Avignon \\
\hline & $8 \dagger$ & 81 & Extra-intestinal infections $\ddagger$ & St Antoine hospital, Paris \\
\hline & $9 \dagger$ & 44 & Urinary tract infection & $\begin{array}{l}\text { Clinical biology laboratory, } \\
\text { Paris }\end{array}$ \\
\hline & 10 & 66 & Extra-intestinal infections $\ddagger$ & Beaujon hospital, Clichy \\
\hline
\end{tabular}

*AIS, animal intestinal strains; HIS, human intestinal strains; HES, human extra-intestinal infection strains. $\dagger$ Random collection.

$\ddagger$ Urinary tract infections, genital infections, lung infections, deep abcess, cholecystitis, septicaemia.

\section{METHODS}

Bacterial strains. The sources of the strains are shown in Table 1. All isolates were cultured in Fernbach flasks containing $500 \mathrm{ml} \mathrm{L}$ broth (Lennox, 1955) without glucose. The flasks were shaken vigorously for $18 \mathrm{~h}$ at $37^{\circ} \mathrm{C}$ in a reciprocating water bath shaker set at about 70 oscillations $\min ^{-1}$.

Electrophoretic analysis. The preparation of extracts, protein estimation, horizontal slab PAGE $(7 \%, \mathrm{w} / \mathrm{v}$, acrylamide; Tris/glycine buffer $\mathrm{pH} 8.6)$, estimation of electrophoretic mobility $\left(M_{F}\right)$ and esterase staining have been described previously (Goullet \& Picard, 1985).

Each $M_{F}$ variant was designated as an allozyme. When an esterase was not detected in a strain, it was recorded as 'null allozyme' (and scored 0). Each distinctive combination of allozymes for the four varieties of esterases was designated as an electrophoretic type $\left(E_{\mathrm{t}}\right)$. In principal components analysis, the weighted electrophoretic type $\left(W E_{i}\right)$ designated the number of strains showing the same electrophoretic type.

Statistical analyses. Principal components analysis, discriminant analysis and analysis of two-way frequency tables ( $\chi^{2}$ test) were done using the Biomedical Programs of the University of California (Dixon, 1981). The electrophoretic data were converted into binary code by considering each allozyme as a variable, occurring in either of two states, i.e. present $=1$ or absent $=0$.

\section{RESULTS AND DISCUSSION}

The electrophoretic relationships between strains were established by multiple runs, comparing esterase bands side by side on the same gel. The $M_{F}$ values were used only comparatively. A total of 59 allozymes were detected (including null allozyme): 7, 13, 18 and 21 for esterases A, B, C and I, respectively.

\section{Distribution of esterase mobilities}

Esterase A showed six allozymes ranging from $M_{F} \simeq 71$ to $M_{F} \simeq 83$ (Table 2), of which 3 occurred most frequently, i.e. those with $M_{F} \simeq 75$ (designated A-75), $M_{F} \simeq 78$ (A-78) and $M_{F} \simeq 81$ (A-81). These included $48.2 \%, 29 \%$ and $13 \%$ of the strains, respectively. For each of these three allozymes, the proportion of organisms varied according to their origin. Thus, $68.3 \%$ of human intestinal strains (HIS) had the allozyme A-75, 37.7\% of strains derived from human extra-intestinal infections (HES) had A-78 and $25.6 \%$ of animal intestinal strains (AIS) had A81. Allozyme A-75 was the most frequently observed among the three populations. The ratio between this allozyme and allozymes A-78 and A-81 served to distinguish the three populations. 
Table 2. Electrophoretic distribution of esterases $A, B, C$ and $I$ in the three populations

The values given are the percentage of strains with each allozyme; particularly significant values are shown in bold type. NA, Null allozyme; AIS, animal intestinal strains; HIS, human intestinal strains; HES, human extra-intestinal infection strains.

\begin{tabular}{|c|c|c|c|c|c|c|c|c|c|c|c|c|}
\hline \multirow[b]{2}{*}{$M_{F}$} & \multicolumn{3}{|c|}{ Esterase A } & \multicolumn{3}{|c|}{ Esterase B } & \multicolumn{3}{|c|}{ Esterase C } & \multicolumn{3}{|c|}{ Esterase I } \\
\hline & AIS & HIS & HES & AIS & HIS & HES & AIS & HIS & HES & AIS & HIS & HES \\
\hline $\begin{array}{l}44 \\
45\end{array}$ & & & & & & & $2 \cdot 8$ & & & & & \\
\hline 46 & & & & & & & 2.8 & $2 \cdot 1$ & & & & \\
\hline 47 & & & & & & & 0.5 & & & & & \\
\hline 48 & & & & & & & $11 \cdot 8$ & $14 \cdot 1$ & $4 \cdot 7$ & & & \\
\hline 49 & & & & & & & & & & & & \\
\hline $\begin{array}{l}50 \\
51\end{array}$ & & & & & & & 1.4 & $2 \cdot 1$ & 0.8 & & & \\
\hline 52 & & & & & & & 1.4 & $2 \cdot 8$ & 0.8 & & & \\
\hline 53 & & & & & & & $3 \cdot 3$ & $6 \cdot 3$ & 5.4 & & & 0.4 \\
\hline 54 & & & & & & & & $5: 6$ & 0.4 & & & \\
\hline 55 & & & & & & & $43 \cdot 1$ & $8 \cdot 5$ & $12 \cdot 1$ & & & 0.4 \\
\hline 56 & & & & & & & 0.5 & & 0.4 & & & \\
\hline 57 & & & & 1.4 & 2.8 & 29.2 & 13.7 & $7 \cdot 0$ & 8.6 & 0.5 & & 0.8 \\
\hline 58 & & & & & & & & & & & 0.7 & 0.4 \\
\hline 59 & & & & & & & 3.8 & $6 \cdot 3$ & $2 \cdot 3$ & 0.5 & & 0.8 \\
\hline 60 & & & & 0.5 & 5.6 & 9.7 & $8 \cdot 1$ & 21.8 & 28.8 & & 9.9 & 5.4 \\
\hline 61 & & & & & & & 0.5 & 0.7 & 0.8 & & & 0.8 \\
\hline 62 & & & & & 1.4 & 4.7 & 0.5 & $2 \cdot 1$ & 4.7 & 1.4 & 2.8 & $5 \cdot 1$ \\
\hline 63 & & & & & & 0.4 & & & 0.8 & 1.9 & $4 \cdot 2$ & 1.6 \\
\hline 64 & & & & & & & & & & 0.9 & & 0.4 \\
\hline 65 & & & & & & & & & & 0.5 & & 0.8 \\
\hline 66 & & & & $2 \cdot 4$ & 0.7 & 1.9 & & & 0.8 & 2.8 & 4.9 & \\
\hline 67 & & & & & & 0.4 & & & & & & 1.2 \\
\hline $\begin{array}{l}68 \\
69\end{array}$ & & & & $11 \cdot 4$ & $16 \cdot 2$ & $4 \cdot 7$ & & & & 11.8 & $8 \cdot 5$ & 8.9 \\
\hline 70 & & & & $58 \cdot 3$ & $61 \cdot 3$ & $33 \cdot 1$ & & & & 38.9 & $23 \cdot 2$ & $31 \cdot 1$ \\
\hline 71 & & & 1.2 & & & & & & & & & \\
\hline 72 & & & 0.8 & 11.4 & 3.5 & 9.7 & & & & $10 \cdot 9$ & $6 \cdot 3$ & $5 \cdot 4$ \\
\hline 73 & & & & 1.9 & 2.8 & $2 \cdot 3$ & & & & $4 \cdot 3$ & $4 \cdot 2$ & $4 \cdot 3$ \\
\hline 74 & & & & $5 \cdot 7$ & 1.4 & 0.4 & & & & & $2 \cdot 1$ & 2.7 \\
\hline 75 & 37.4 & 68.3 & $45 \cdot 9$ & 0.5 & & & & & & $1 \cdot 4$ & $5 \cdot 6$ & $3 \cdot 1$ \\
\hline $\begin{array}{l}76 \\
77\end{array}$ & & & & & & & & & & & & \\
\hline 78 & $28 \cdot 0$ & 14.8 & 37.7 & & & & & & & & & $2 \cdot 7$ \\
\hline $\begin{array}{l}79 \\
80\end{array}$ & & & & & & & & & & & & \\
\hline 81 & $25 \cdot 6$ & 8.5 & 5.1 & & & & & & & & & \\
\hline 82 & & & & & & & & & & & & \\
\hline 83 & $2 \cdot 4$ & & 0.4 & & & & & & & & & \\
\hline $\mathrm{NA}$ & 6.6 & 8.5 & 8.9 & 6.6 & $4 \cdot 2$ & 3.5 & 5.7 & $20 \cdot 4$ & 28.8 & $24 \cdot 2$ & 27.5 & 19.8 \\
\hline
\end{tabular}

Thus, the ratio A-81/A-75 was higher for animal strains (0.68) than for human strains $(0.12$ for HIS and 0.11 for HES), whereas the ratio A-78/A-75 was higher for HES (0.82) than for HIS $(0.21)$. Five strains originating from wild animals and one HES had an unusual mobility $\left(M_{F} \simeq 83\right)$ of esterase A.

Esterase B, which was recently purified and designated as carboxylesterase B (Goullet et al., 1984), showed 12 allozymes, divided among two groups (Table 2). (i) a Gaussian distribution was observed for 450 strains ( $74 \%$ of the total) with $M_{F} \simeq 66$ to $M_{F} \simeq 75$. The most frequently occurring allozyme was $M_{F} \simeq 70$; in this case the number of strains producing B-70 was higher in AIS and HIS (58 and $61 \%$ ) than in HES (33\%). Esterase B appeared to be more symmetrically distributed (from $M_{F} \simeq 66$ to $M_{F} \simeq 75$ ) in AIS than in HIS and HES, and migrated more 
Table 3. Pearson $\chi^{2}$ calculated for each esterase

$\begin{array}{cccc}\text { Esterase } & \begin{array}{c}\text { Pearson } \\ \chi^{2}\end{array} & \begin{array}{c}\text { Degree of } \\ \text { freedom }\end{array} & P \text {-value } \\ \text { B } & 175 & 24 & 0.999 \\ \text { A } & 88 & 12 & 0.999 \\ \text { C } & 205 & 34 & 0.999 \\ \text { I } & 78 & 40 & 0.999\end{array}$

Table 4. Genetic diversity $(H)$ of esterases $A, B, C$ and $I$ in each of the five random groups of E. coli

\begin{tabular}{cccccc}
\multicolumn{5}{c}{$H=1-\Sigma x_{i}^{2}$ where } & \multicolumn{5}{c}{ is the frequency for each allozyme. } \\
& A & B & C & I & Mean \\
AIS: group 1 & 0.721 & 0.617 & 0.629 & 0.691 & 0.66 \\
HIS: group 4 & 0.438 & 0.525 & 0.832 & 0.812 & 0.65 \\
HES: group 7 & 0.609 & 0.782 & 0.731 & 0.798 & 0.73 \\
HES: group 8 & 0.618 & 0.771 & 0.801 & 0.819 & 0.75 \\
HES: group 9 & 0.665 & 0.745 & 0.792 & 0.813 & 0.75
\end{tabular}

frequently ( $M_{F} \simeq 72$ for HES and $M_{F} \simeq 68$ for HIS). The faster migrating allozymes of esterase B $\left(M_{F}>72\right)$ were obtained predominantly from AIS. (ii) There was an increasing slope from $M_{F} \simeq 63$ to $M_{F} \simeq 57$ clearly separated from the Gaussian distribution by a free interval of two $M_{F}$ units. A striking result was that this increasing slope was concerned principally with HES. The proportion of strains producing B-57 were $29 \%$ for HES, $2.8 \%$ for HIS and $1.4 \%$ for AIS. In the following paper (Goullet \& Picard, 1986) we describe the resolved electrophoretic distribution of carboxylesterase $B$ in a random collection of strains of human origin using a twodimensional electrophoretic profile (Goullet \& Picard, 1985) and demonstrate that production of $\alpha$-haemolysin and mannose resistant haemagglutinin were significantly higher in pathogenic strains showing slow mobilities $\left(M_{F} \simeq 63\right.$ to $\left.M_{F} \simeq 57\right)$ of esterase B.

Esterase $C$ showed 17 allozymes $\left(M_{F} \simeq 44\right.$ to $M_{F} \simeq 66$ ) (Table 2 ). More than $51 \%$ of the strains were included in the three allozymes $M_{F} \simeq 48\left(9.3 \%\right.$ of the total), $M_{F} \simeq 55(22 \%$ of the isolates) and $M_{F} \simeq 60$ (20\% of the strains). For each of these three allozymes, the distribution of the organisms varied with the origin. Thus, $43 \%$ of AIS had allozyme C-55, $14 \%$ of HIS had C-48 and $28.8 \%$ had C-60. A higher percentage of null allozyme was observed for HES.

Esterase I showed 20 allozymes (Table 2), divided as follows. (i) There was a Gaussian distribution from $M_{F} \simeq 65$ to $M_{F} \simeq 78$, including 392 strains of diverse origin but with $70.6 \%$ AIS. These had a frequent allozyme $M_{F} \simeq 70$. (ii) There was an increasing slope from $M_{F} \simeq 64$ to $M_{F} \simeq 60$. Here allozyme I-60 was recovered exclusively in human strains, and principally in HIS.

Pearson $\chi^{2}$ test. For each of the four esterases, a table of frequency of the various allozymes for each populations (AIS, HIS and HES) was analysed. The Pearson $\chi^{2}$ value calculated from each contingency table appeared to be highly significant at $P=0.999$ (Table 3 ).

\section{Genetic diversity in random groups}

Genetic diversity coefficients (GDCs) (Nei, 1975; Selander \& Levin, 1980) determined for the five random groups of organisms (Table 1) have been included in Table 4. Mean GDCs of AIS (group 1, corresponding to six mammalian species and one bird species) and of HIS (group 4) were very similar: 0.66 and 0.65 , respectively. These values were lower than those of the HES groups $7,8,9$, i.e. $0.73,0.75$ and 0.75 . The individual GDC of each esterase was distinct from AIS to HIS. The similarity between the mean GDCs of AIS and of HIS was explained by the fact that increasing values of GDCs of esterases A and B from HIS to AIS were compensated by decreasing values of GDCs of esterases $C$ and I. The GDCs correlated with the electrophoretic distribution (Table 2). Thus, the higher GDCs of esterases A and B in AIS reflected the higher 

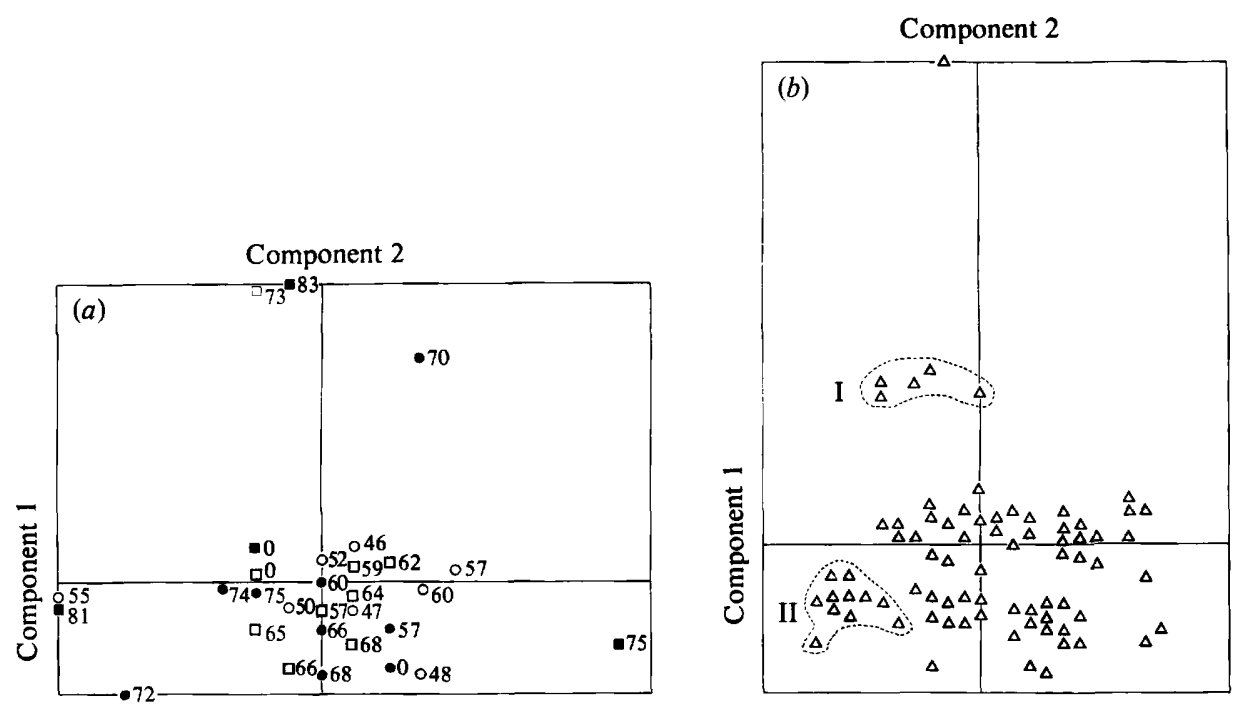

Fig. 1. Principal components analysis of the AIS. (a) Plot of score of allozymes for the first two principal components: $\square$, allozyme of esterase $A$; $O$, allozyme of esterase $B$; $O$, allozyme of esterase C; $\square$, allozyme of esterase I. (b) $\triangle$, Plot of score of weighted electrophoretic types for the first two principal components. For clarity, some of the allozymes from the various esterases which were projected near the origin of the axes have been omitted from the Figure.

frequency of allozyme A-81 and of allozyme B having $M_{F}$ values $>72$, whereas the higher value of GDC of esterase B in HES reflected the higher percentage of slow esterase B mobilities $\left(M_{F} \simeq 57\right.$ to $M_{F} \simeq 63$ ). Esterases $\mathrm{C}$ and I showed smaller GDCs in AIS than in human (commensal and pathogenic) groups.

\section{Principal components analysis}

Principal components analysis was done using the data obtained from the ten bacterial groups (Table 1).

Animal intestinal strains. The first two principal components accounted for $9 \%$ of the total variance. Projections of different allozymes (Fig. $1 a$ ) on the first two axes revealed that the first component opposed allozymes A-81, C-55 and B-72 to allozyme A-75, and that allozymes I-73, $\mathrm{A}-83$ and B-70 were distinguished by the second component. Projections of $W E_{\mathrm{t}}$ (Fig. $1 \mathrm{~b}$ ) distinguished one group (I) displayed by component 2 with high mobility of esterase A consisting of electrophoretic types recovered from wild animal strains, and another group (II) opposed to other strains by component 1 and exhibiting allozyme B-72.

Human intestinal strains. The first two principal components accounted for $9.1 \%$ of the total variance. Projection of different allozymes (Fig. $2 a$ ) on the first two axes showed that component 1 opposed allozymes B-72 and A-81 to allozymes A-75 and B-70, and that allozymes B-57, B-60, I-60 and C-0 were distinguished by component 2. Projection of $W E_{\mathrm{t}}$ (Fig. $2 b$ ) distinguished one group (I) opposed to other strains by component 1 and exhibiting allozymes A-81 and B-72 frequently observed in AIS and another group (II) of 12 weighted electrophoretic types displayed by component 2 which exhibited allozymes frequently observed in HES (B-57, B-60, B-62 and C-0). These strains could be potentially extra-intestinal invasive organisms.

Strains derived from human extra-intestinal infections. The first two principal components accounted for $8.6 \%$ of the total variance. Projection of different allozymes on the first two axes showed that component 1 opposed allozymes A-78, B-57 and C-60 to allozymes A-75 and B-70. 

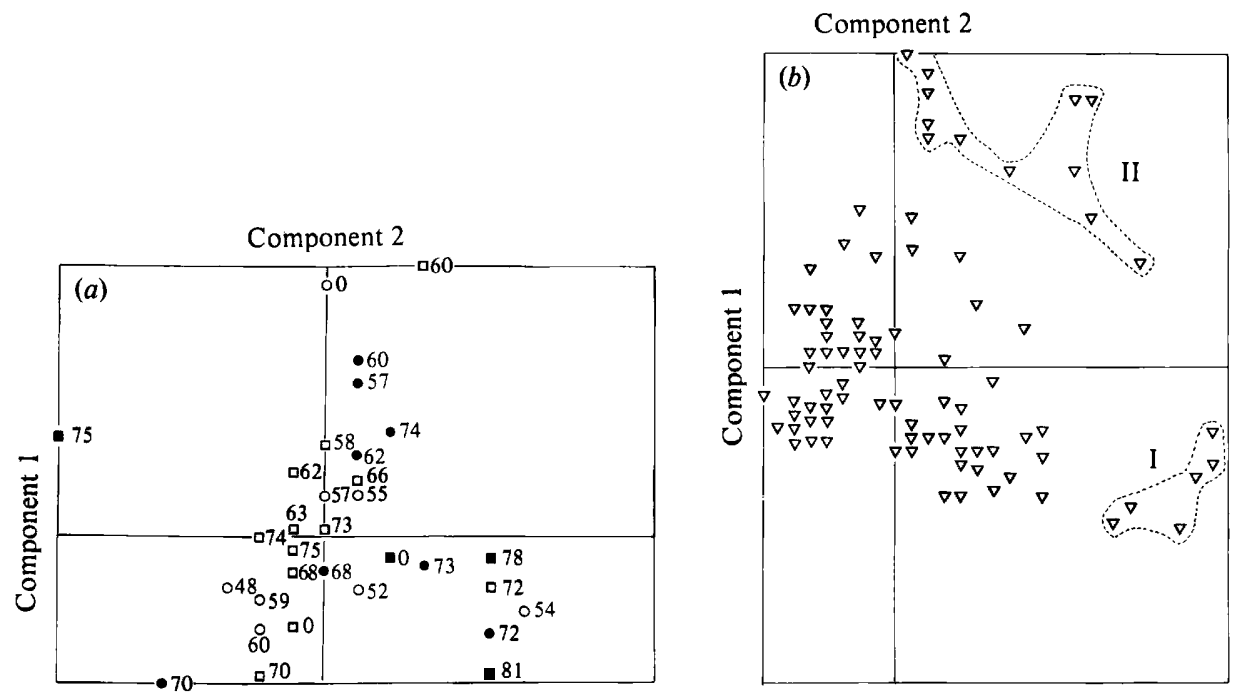

Fig. 2. Principal components analysis of the HIS. (a) Plot of score of allozymes for the first two principal components: symbols as in legend to Fig. 1. (b) $\nabla$, Plot of score of weighted electrophoretic types for the first two principal components. For clarity, some of the allozymes from the various esterases which were projected near the origin of the axes have been omitted from the Figure.
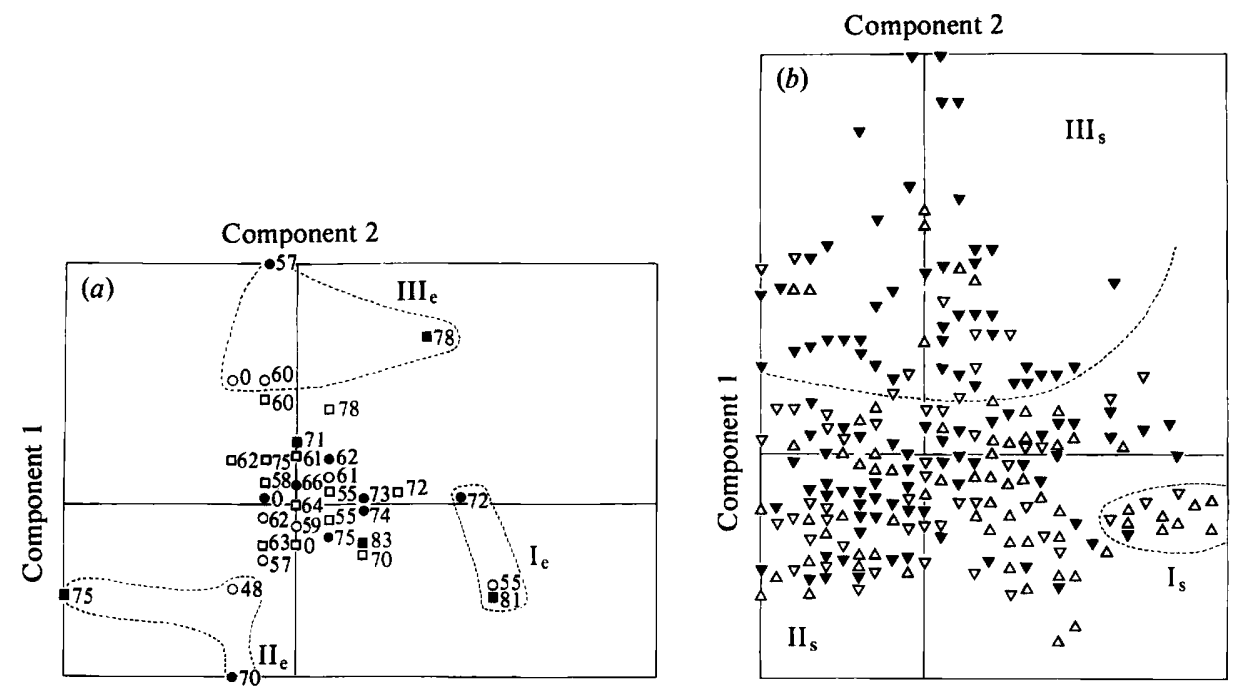

Fig. 3. Principal components analysis of the 610 E. coli strains. (a) Plot of score of allozymes for the first two principal components: symbols as in legend to Fig. 1. (b) Plot of score of weighted electrophoretic types for the first two principal components: $\triangle$, AIS; $\nabla$, HIS; $\nabla$, HES. For clarity, some of the allozymes from the various esterases which were projected near the origin of the axes have been omitted from the Figure.

This confirmed the electrophoretic distribution of esterase B (Table 2) which showed the clearcut division into slow and fast mobilities. Weighted electrophoretic types were projected in a circle centred on the origin of the axes.

The 610 strains of E. coli. The first two principal components accounted for $8 \cdot 1 \%$ of the total variance. Projections of different allozymes (Fig. $3 a$ ) on the first two axes revealed three major groups: group $I_{e}$, consisting of allozymes B-72, A-81 and C-55, opposed to group $\mathrm{II}_{e}$, with allozymes B-70, A-75 and C-48, by component 1 ; and group III $_{e}$, with allozymes B-57, A-78, 
Table 5. Numbers of strains recovered in the most frequently observed electrophoretic types distinguished within the three populations of $E$. coli

\begin{tabular}{|c|c|c|c|}
\hline Population of $E$. coli & Allozyme B & $E_{\mathrm{tBA}}$ & $E_{\mathrm{tBAC}}$ \\
\hline AIS : $211(100 \%)$ & $\begin{array}{l}\text { B-70: } 123(58 \cdot 3 \%) \\
\text { B-72: } 24(11.4 \%)\end{array}$ & $\begin{array}{l}\text { A-75: } 53(25 \%) \\
\text { A-78: } 37(17.5 \%) \\
\text { A-81: } 21(9.9 \%) \\
\text { A-81: } 18(8.5 \%)\end{array}$ & $\begin{array}{l}\text { C-57: } 14(6.6 \%) \\
\text { C-55: } 22(10.5 \%) \\
\text { C-55: } 15(7.1 \%) \\
C-55: 17(8.1 \%)\end{array}$ \\
\hline HIS : $142(100 \%)$ & B-70: $87(61.3 \%)$ & A-75: $64(45 \%)$ & $\begin{array}{l}C-0: 13(9.2 \%) \\
C-48: 13(9 \cdot 2 \%) \\
C-60: 17(12 \%)\end{array}$ \\
\hline HES : $257(100 \%)$ & $\begin{array}{l}\text { B-70: } 85(33.1 \%) \\
\text { B-57: } 75(29 \%)\end{array}$ & $\begin{array}{l}\text { A-75: } 53(20.6 \%) \\
\text { A-75: } 30(11.7 \%) \\
\text { A-78: } 42(16.4 \%)\end{array}$ & $\begin{array}{l}\text { C-0: } 13(5 \%) \\
C-0: 13(5 \%) \\
C-60: 14(5.4 \%) \\
C-60: 32(12.45 \%)\end{array}$ \\
\hline
\end{tabular}

C-60 and C-0, distinguished by component 2. Projections of $W E_{\mathrm{t}}$ (Fig. $3 b$ ) distinguished three groups. One group, $I_{s}$, of weighted electrophoretic types comprised allozymes B-72, A-81 and C-55 and was opposed by component 1 to a second group, $\mathrm{II}_{\mathrm{s}}$, of weighted electrophoretic types which comprised allozymes B-70 and A-75 and was composed of strains of the three populations; a third group, $\mathrm{III}_{\mathrm{s}}$, of 104 weighted electrophoretic types, displayed by component 2, was composed of $88 \mathrm{HES}$ ( $32 \%$ of HES), 12 HIS (the same strains distinguished by principal components analysis of HIS) and four AIS, and comprised allozymes B-57, A-78 and C-60.

From the principal components analysis of AIS, HIS, HES and 610 strains of E. coli, three groups of allozymes were distinguished: (i) allozyme B-72 associated with A-81 and C-55; (ii) allozymes B-57 and B-60 associated with A-78, C-60 and C-0; and (iii) allozyme B-70 associated with A-75 and C-48. These three associations corresponded to three groups of strains: the first, frequently isolated from animals, exhibited the same $M_{F}$ values of esterase B and A as Shigella flexneri strains of serotype 6 and some strains of Shigella boydii (Goullet, 1980; Goullet et al., 1983); the second, characterized by slow mobilities of esterase B, was largely represented in HES and rarely in HIS and AIS; the third, characterized by prominence of the most common mobilities of esterases $\mathrm{B}$ and $\mathrm{A}\left(M_{F} \simeq 70\right.$ and $M_{F} \simeq 75$, respectively), was frequently recovered in the three populations.

\section{Electrophoretic types}

Among the 610 strains, 316 distinct combinations of allozymes for the four esterases (electrophoretic types B, A, C, I: $E_{\mathrm{tBACl}}$ ) were characterized. However, the allozymes which were found to be the most discriminating by principal components analysis were those of esterases B, A and C. As shown esterase I (Table 2) appeared to be a less discriminating enzyme for the precise origin of strains. Consequently, we have disregarded allozymes of this esterase, and examined only electrophoretic types B, A and C. We have considered within the three populations the electrophoretic types $\mathrm{B}, \mathrm{A}, \mathrm{C}\left(E_{\mathrm{tBAC}}\right)$ which grouped individually at least $5 \%$ of strains (Table 5). Of the AIS, $32.4 \%$ were distributed in four distinct $E_{\mathrm{BAC}}$; the electrophoretic type B-72, A-81, C-55 represented $8.1 \%$ of strains and only $1.4 \%$ and $2.8 \%$ of HES and HIS, and appeared to be an electrophoretic type more frequently recovered in animal strains. Of the AIS, $25 \%$ and $45 \%$ of the HES exhibited allozymes B-70 and A-75 but these two groups of strains were distinguished by the mobility of esterase C ( $M_{F} \simeq 57$ for AIS and $M_{F} \simeq 48$ and 60 for HIS). Of the HES, $29 \%$ produced esterase B with $M_{F} \simeq 57$; they were distributed in three $E_{\mathrm{tBAC}}$ including allozymes C- 60 and C- 0 exclusively, whereas these $E_{\mathrm{tBAC}}$ were rarely observed in AIS and HES $(1.5 \%$ and $2.7 \%$, respectively). This stereotyped distribution conferred a particular character to human pathogenic strains.

The GDCs of the four esterases, calculated according to the $316 E_{\mathrm{tBACl}}$, were 0.812 for esterase B, 0.706 for esterase A, 0.870 for esterase $C$ and 0.848 for esterase I. The mean of these GDCs $(0.81)$ was higher than the value (0.52) reported by Ochman et al. (1983) for allozymes of 12 enzymes studied in $1608 \mathrm{E}$. coli isolates; however, individual GDCs of esterases were similar to 
Table 6. Discriminant functions $(F)$ used by discriminant analysis to classify the 610 observations within the three populations of E. coli

$\begin{array}{lccrcr}\begin{array}{c}\text { Allozyme } \\ \text { used }\end{array} & \boldsymbol{F} & \begin{array}{c}\text { Selection } \\ \text { order }\end{array} & \text { HES } & \text { HIS } & \text { AIS } \\ \text { B-57 } & 50.4 & 1 & 5.88 & 2.07 & 3.14 \\ \text { C-55 } & 37.45 & 2 & 3.30 & 2.72 & 5.76 \\ \text { B-60 } & 21.4 & 3 & 2.45 & 0.10 & -0.92 \\ \text { C-57 } & 12.87 & 7 & 3.53 & 2.47 & 4.82 \\ \text { I-60 } & 11.42 & 5 & -1.94 & 1 \cdot 11 & -1.13 \\ \text { B-62 } & 9.80 & 4 & 4 \cdot 49 & 1.57 & 1.24 \\ \text { C-54 } & 9.51 & 9 & 2.32 & 6.48 & 2.49 \\ \text { C-44 } & 8.69 & 10 & 4.38 & 3.97 & 8.72 \\ \text { A-75 } & 7.15 & 8 & 3.00 & 4.02 & 3.11 \\ \text { B-72 } & 6.56 & 11 & 3.36 & 1.70 & 2.28 \\ \text { C-48 } & 5.69 & 14 & 2.31 & 2.42 & 3.72 \\ \text { I-70 } & 5.52 & 12 & 2.51 & 1.72 & 2.56 \\ \text { C-46 } & 5.39 & 15 & 2.55 & 3.69 & 5.77 \\ \text { A-81 } & 5.08 & 13 & 1.06 & 2.07 & 2.29 \\ \text { C-0 } & 4.96 & 6 & 3.77 & 2.65 & 3.03 \\ \text { B-74 } & 4.19 & 16 & 2.12 & 2.32 & 4.22\end{array}$

Table 7. Results of the classification according to discriminant analysis calculations from the 610 observations

$\begin{array}{lcccc} & \begin{array}{c}\text { Percentage of strains } \\ \text { correctly classified }\end{array} & \begin{array}{c}\text { Calculated } \\ \text { HES }\end{array} & \begin{array}{c}\text { Calculated } \\ \text { HIS }\end{array} & \begin{array}{c}\text { Calculated } \\ \text { AIS }\end{array} \\ \text { HES strains (257) } & 59 \cdot 5 & 153 & 60 & 44 \\ \text { HIS strains (142) } & 69.7 & 15 & 99 & 28 \\ \text { AIS strains (211) } & 69.7 & 21 & 43 & 147 \\ & & 189 & 202 & 219\end{array}$

those of the four most polymorphic enzymes: alcohol dehydrogenase (0.729), 6-phosphogluconate dehydrogenase $(0.715), \beta$-galactosidase $(0.893)$ and mannose phosphate isomerase $(0.710)$.

The high polymorphism of $E$. coli esterases may be resolved further by using a twodimensional electrophoretic profile (Goullet \& Picard, 1985; Picard \& Goullet, 1985).

\section{Discriminant analysis}

Using the 610 strains and the 59 allozymes, discriminant analysis was used to distinguish AIS, HES and HIS (Table 6 and 7). Sixteen allozymes were selected for discriminant functions (Table 6); the most significant of these were B-57, C-55, B-60, C-57 and I-60 (exclusively recovered in strains from human origin), and B-62. Application of the discriminant functions (corresponding to coefficients presented in Table 6) to the 610 strains enabled the correct classification of $59.5 \%, 69.7 \%$ and $69.7 \%$ of HES, HIS and AIS, respectively (Table 7 ). Whereas $40 \%$ of HES were classified within AIS and HIS, only $10 \%$ of AIS and HIS were classified in HES.

Both principal components analysis and discriminant analysis demonstrated that the three populations of $E$. coli strains examined in the present work may be distinguished by esterase electrophoretic polymorphism. The validity of these data was supported by the fact that the samples were very diverse in origin (see Table 1). It would be interesting to compare these results with those obtained with strains from other parts of the world.

We thank Professor G. Daguet from St Antoine Hospital, Dr H. Sep Hieng from Durance Hospital and Dr J. P. Timsit for human clinical strains; Professors A. Thabault and M. Meyran from Begin Hospital for human intestinal strains; Dr C. Branger, Dr M. Picard and Office National des Forêts de la forêt de Fontainebleau for animal intestinal strains; Madame C. Gaillard for technical assistance; Monsieur P. Chollet and Mademoiselle A. Antoine from Rhones Poulenc Recherches-Centre d'Aubervilliers for computed calculations; and Professor A. 
Jacquard and Dr A. Chaventré from Institut National d'Etudes Démographiques for useful discussions.

This work was supported by grants from the Conseil Scientifique de la Faculté Xavier Bichat (Université Paris VII) and from the Fondation pour la Recherche Médicale Française.

\section{REFERENCES}

BRenNer, D. J. \& Falkow, S. (1971). Molecular relationships among members of the Enterobacteriaceae. Advances in Genetics 16, 81-118.

Brenner, D. J., Fanning, G. R., Johnson, K. E., Citarella, R. V. \& Falkow, S. (1969). Polynucleotide sequence relationships among members of Enterobacteriaceae. Journal of Bacteriology 98, 637650.

Brenner, D. J., Fanning, G. R., Skerman, F. J. \& FALKow, S. (1972). Polynucleotide sequence divergence among strains of Escherichia coli and closely related organisms. Journal of Bacteriology 109, 953965.

DiXON, W. (1981). B.M.D.P. Statistical Software. Berkeley, California : University of California Press.

Gillespie, J. H. \& LANGley, C. H. (1974). A general model to account for enzyme variation in natural populations. Genetics 76, 837-884.

Goullet, PH. (1973). An esterase zymogram of Escherichia coli. Journal of General Microbiology 77, 27-35.

Goullet, PH. (1980). Esterase electrophoretic pattern relatedness between Shigella species and Escherichia coli. Journal of General Microbiology 117, 493-500.

Goullet, PH. (1981). Characterization of Serratia odorifera, $S$. fonticola and $S$. ficaria by the electrophoretic patterns of their esterases. Journal of General Microbiology 127, 161-167.

Goullet, PH. \& PiCARD, B. (1984a). Typage életrophorétique des esterases d'Escherichia coli au cours de septicémies. La Presse Médicale 13, 1079-1081.

Goullet, PH. \& Picard, B. (1984b). Distinctive electrophoretic and isoelectric focusing patterns of esterases from Yersinia enterocolitica and Yersinia pseudotuberculosis. Journal of General Microbiology 130, 1471-1480.

Goullet, PH. \& PiCARD, B. (1985). A two-dimensional electrophoretic profile for bacterial esterases. Electrophoresis 6, 132-135.
Goullet, Ph. \& PiCard, B. (1986). Highly pathogenic strains of Escherichia coli revealed by distinct electrophoretic pattern of carboxylesterase B. Journal of General Microbiology 132, 1853-1858.

Goullet, Ph., Picard, B. \& Toucas, M. (1983). Differenciation du sérotype 6 des sérotypes $1-5$ de Shigella flexneri par électrophorese et focalisation isoélectrique de leurs estérases. Annales de microbiologie 134B, 269-276.

Goullet, Ph., Picard, B. \& Laget, P. F. (1984). Purification and properties of carboxylesterase B of Escherichia coli. Annales de Microbiologie 135A, 375387.

LENNOX, E. S. (1955). Transduction of linked genetic characters of the host by bacteriophage PI. Virology 1, 190-206.

MilkmaN, R. (1973). Electrophoretic variation in Escherichia coli from natural sources. Science 182, 1024-1026.

NeI, M. (1975). Molecular Population Genetics and Evolution. New York: Elsevier.

Ochman, H., Whittam, T. S., Caugant, D. A. \& SELANDER, R. K. (1983). Enzyme polymorphism and genetic population structure in Escherichia coli and Shigella. Journal of General Microbiology 129, 27152726.

PiCARD, B. \& Goullet, Ph. (1985). Comparative electrophoretic profiles of esterases, and of glutamate, lactate and malate dehydrogenases, from Aeromonas hydrophila, $A$. caviae and $A$. sobria. Journal of General Microbiology 131, 3385-3391.

Selander, R. K. \& Levin, B. R. (1980). Genetic diversity and structure in Escherichia coli populations. Science 210, 545-547.

Whittam, T. S., Ochman, H. \& Selander, R. K. (1983). Multilocus genetic structure in natural populations of Escherichia coli. Proceedings of the National Academy of Sciences of the United States of America 80, 1751-1755. 